\title{
Evaporation and Temperature Changes in the English Channel.
}

\author{
By \\ H. W. Harvey, M.A., \\ Hydrographer at the Plymouth Laboratory.
}

With Four Figures in the Text.

Since April, 1921, observations of temperature and salinity have been made at depths from top to bottom of the sea at Station E1, 20 miles to the south-west of Plymouth, where the depth is 70 metres. These observations already throw some light on the causes of different sea temperatures during the same month in different years. As these temperature differences from year to year play an all-important part in the life of cold-blooded marine animals (1), it is of particular interest not only to follow their seasonal changes, but to arrive as far as possible at the causes which govern them.

Changes in salinity and the temperature conditions during 1921 showed a marked inflow of warm highly saline Atlantic water into the English Channel, and a very marked inflow into the El area during September, October and November of that year (2). From that time until the end of 1923 there has been an irregular fall in salinity of the water at E1.

A general consideration of the salinity data available points to no very extensive movement of the water masses in this E1 area during the years 1922 and 1923, although extensive movements took place further south (3).

If, as indicated, the water has not been subject to marked movement other than that due to the tides, it makes this period of particular value in attempting to define factors other than big inflows of water from other areas, which cause variations from the normal in the annual temperature change of the sea.

For the purpose of investigating the effect of meteorological conditions on the temperature of the water occupying the area within, say, 5 or 6 miles north and south and 10 or 20 miles east and west of Station E1, it is assumed in the following calculations that the whole 


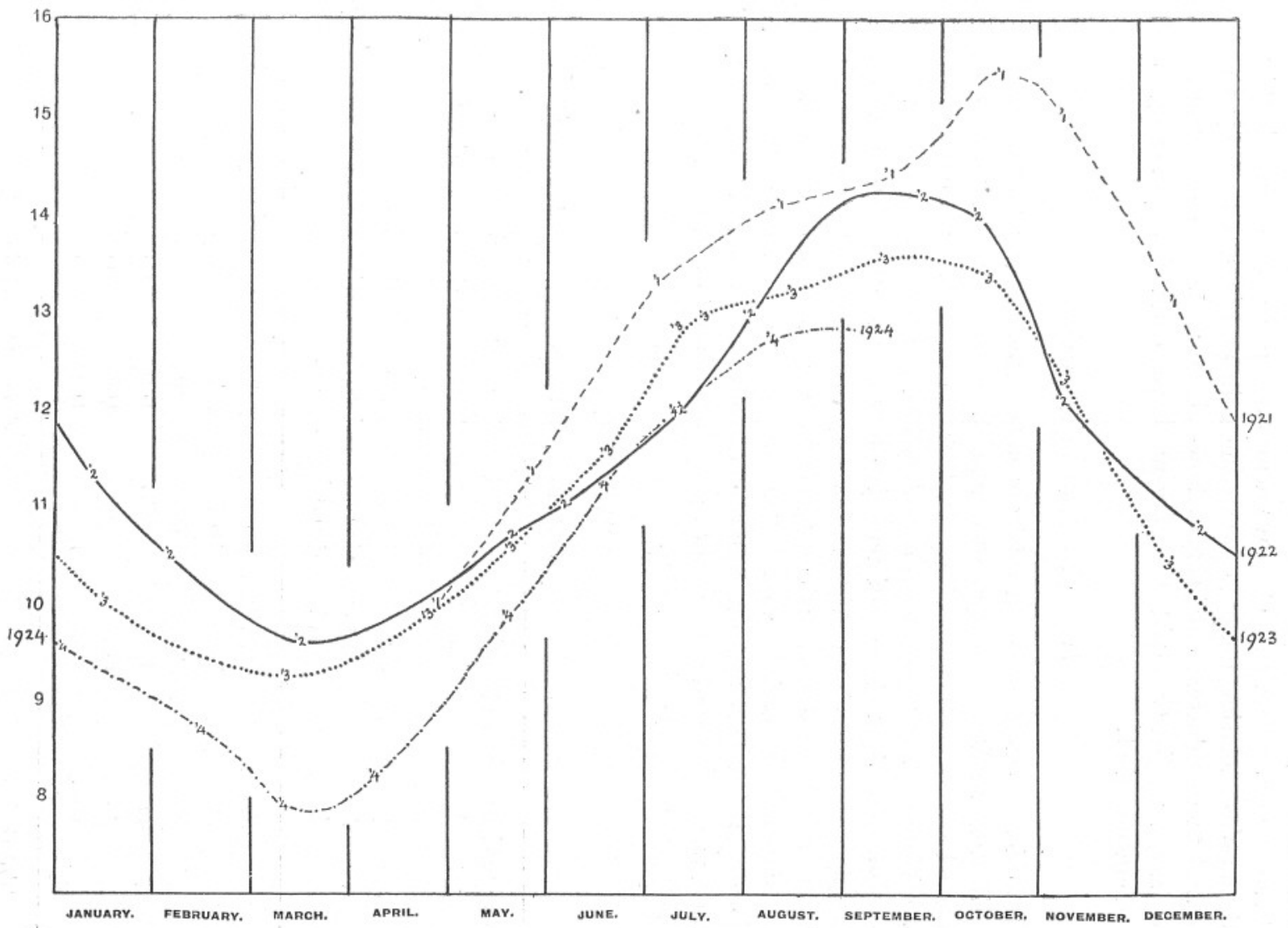

Fic. 1.-Temperature in degrees centigrade of a column of water at Station E1, from top to bottom, as if completely mixed, for the years 1921, 1922, 1923, 1924 
mass of water did not move bodily away to be replaced by water from other areas which had been subjected to different meteorological conditions.

That a certain amount of movement took place is beyond doubt; but the close relation found between the gain and loss of heat by the sea and meteorological conditions, shows, I think, that the movement was not sufficiently rapid to prevent local conditions showing a pronounced effect.

\section{Gain and Loss of Heat.}

In order to arrive at the quantity of heat gained or lost by the water at El from month to month, assuming that the water had not been replaced by water from other areas, the temperatures of a column of water from top to bottom, as if completely mixed, were calculated from the observations made at different depths and the values so obtained were plotted against time. From a fair curve drawn through these points (Fig. 1, p. 679), Table I was constructed. Assuming that all the heat lost and gained passed through the surface, the amounts in gram calories passing through one square centimetre of surface during each month were calculated and are shown in Table II as the mean daily loss or gain for each calendar month.

\section{TABLE I.}

1921-22. 1922-23. 1923-24. 1924-25.

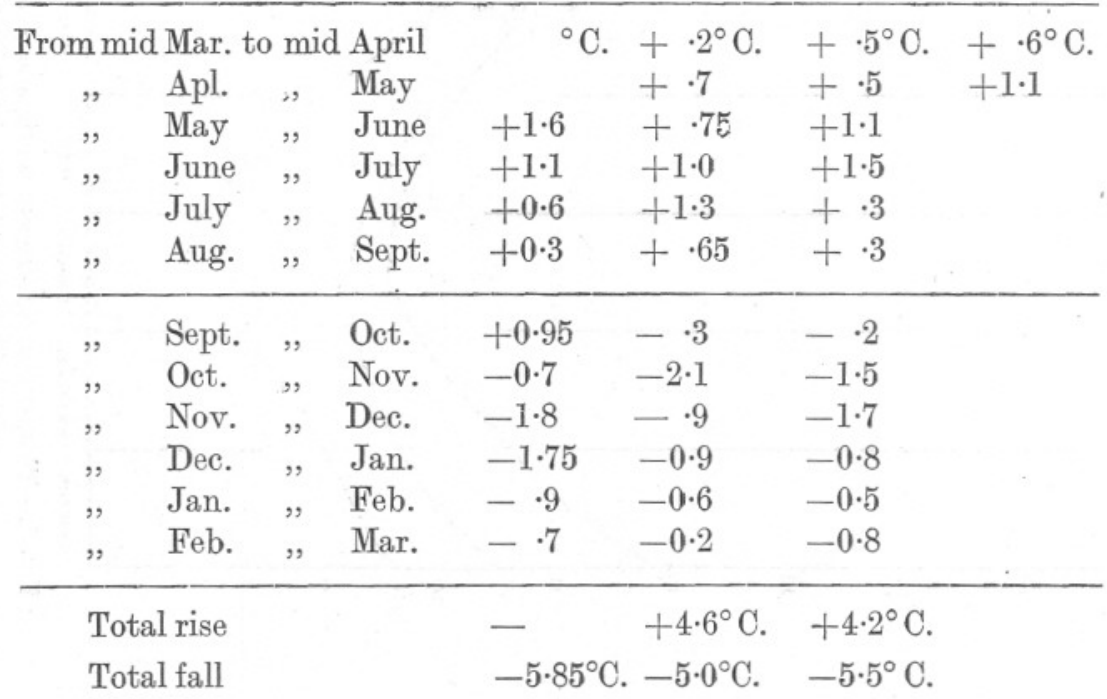

Change in temperature of column of water top to bottom at Station E1. 


\section{TABLE II.}

\begin{tabular}{|c|c|c|c|c|c|}
\hline & $\begin{array}{l}\text { Temperature } \\
\text { change of whole } \\
\text { column of water } \\
\text { during calendar } \\
\text { month. } \\
=\Delta \mathrm{T} .\end{array}$ & $\begin{array}{l}\text { Mean daily loss } \\
\text { er gain in heat } \\
\mathrm{r} \text { of column } 1 \mathrm{sq} . \\
\mathrm{r} \text { cm. section in } \\
\text { gram. calories. } \\
=\mathrm{C} .\end{array}$ & $\begin{array}{l}\text { Solar radiation } \\
\text { recorded at } \$ \text {. } \\
\text { Kensington in } \\
\text { gram calories } \\
\text { per sq. cm. of } \\
\text { horizontal sur- } \\
\text { face per day. } \\
=R \text {. }\end{array}$ & $\begin{array}{l}\text { Calculated mean } \\
\text { daily gain or } \\
\text { loss of heat per } \\
\text { sq. cm. due to } \\
\text { evaporation, totc. } \\
\text { (C - R). } \\
=\mathrm{E} \text {. }\end{array}$ & $\begin{array}{l}\text { Mean aqueous } \\
\text { vapour pres- } \\
\text { sure of surface } \\
\text { water at E1 less } \\
\text { that of air at } \\
\text { Cattewater Air } \\
\text { Station. } \\
\text { Ps-Pa. }\end{array}$ \\
\hline May, 1921 & . $\quad+1 \cdot 5^{\circ} \mathrm{C}$. & $\begin{array}{r}\text { cals. } \\
+339\end{array}$ & $\begin{array}{l}\text { eals. } \\
359\end{array}$ & $\begin{array}{r}\text { cals. } \\
-\quad 20\end{array}$ & \\
\hline June & . +1.5 & +350 & 411 & -61 & \\
\hline July & . +.65 & +147 & 394 & -247 & \\
\hline Aug. & $\cdot+\cdot 35$ & +79 & 284 & -205 & \\
\hline Sept. & $\cdot+5 \mathrm{~m}$ & $\begin{array}{l}\text { marked water } \\
\text { movement }\end{array}$ & no record & & \\
\hline Oct. & $\cdot \quad+\cdot 4$ & ," & $"$ & & $2 \cdot 6$ \\
\hline Nov. & . $-1 \cdot 45$ & , & , & & $4 \cdot 7$ \\
\hline Dec. & . $-1 \cdot 8$ & & , & & $3 \cdot 4$ \\
\hline Jan., 1922 & . $-1 \cdot 3$ & & , & & $2 \cdot 5$ \\
\hline Feb. . & . -8 & & , & & $2 \cdot 2$ \\
\hline Mar. & . -3 & -68 & 127 & -195 & $2 \cdot 9$ \\
\hline April &.+5 & +117 & 231 & -114 & $3 \cdot 0$ \\
\hline May. & $\cdot \quad+\cdot 7$ & +158 & 361 & -203 & \\
\hline June &.+75 & +175 & 326 & -151 & \\
\hline July & . $\quad+1 \cdot 2$ & +271 & 267 & +4 & \\
\hline Aug. & . +1.05 & +247 & 244 & +3 & \\
\hline Sept. & $\cdot+3$ & +70 & 186 & -116 & $2 \cdot 3$ \\
\hline Oct. & . $+1 \cdot 4$ & -316 & 75 & -391 & $4 \cdot 2$ \\
\hline Nov. & . -1.5 & -350 & 46 & -396 & $3 \cdot 1$ \\
\hline Dec. & . $\quad-.9$ & -203 & 47 & -250 & $2 \cdot 4$ \\
\hline Jan., 1923 & $. \quad-\cdot 7$ & -158 & 41 & -199 & $2 \cdot 2$ \\
\hline Feb. & . $\quad-4$ & -97 & 65 & -162 & $1 \cdot 4$ \\
\hline Mar. & . +1 & +22 & 92 & -70 & $1 \cdot 4$ \\
\hline April &.+6 & +140 & 142 & -2 & $1 \cdot 8$ \\
\hline May &.+8 & +180 & 239 & -59 & \\
\hline June & . $\quad+1 \cdot 4$ & +327 & 254 & +73 & \\
\hline July & . +9 & +203 & 337 & -134 & \\
\hline Aug. &.+3 & +68 & 341 & -273 & \\
\hline Sept. &.+1 & +23 & 223 & -200 & $2 \cdot 4$ \\
\hline Oct. & $. \quad-7$ & -158 & 104 & -262 & $2 \cdot 7$ \\
\hline Nov. & . $-2 \cdot 0$ & -452 & 46 & -498 & $4 \cdot 0$ \\
\hline Dec. & . $-1 \cdot 2$ & -271 & 21 & -292 & $2 \cdot 0$ \\
\hline Jan., 1924 & . $\quad-\cdot 7$ & -163 & 23 & -186 & $1 \cdot 4$ \\
\hline Feb. . & $. \quad-6$ & -150 & 46 . & -196 & $1 \cdot 1$ \\
\hline
\end{tabular}


TABLE II-continued.

\begin{tabular}{|c|c|c|c|c|c|c|c|}
\hline & & & $\begin{array}{l}\text { Temperature } \\
\text { changeo whole } \\
\text { column of water } \\
\text { during calendar } \\
\text { month. } \\
=\Delta \mathrm{T} \text {. }\end{array}$ & $\begin{array}{l}\text { Mean dailly loss } \\
\text { or gain in heat } \\
\text { of column } 1 \mathrm{sq} \text {. } \\
\mathrm{cm} \text {. section in } \\
\text { gram. calories. } \\
\text { =C. }\end{array}$ & $\begin{array}{l}\text { Solar radiation } \\
\text { recorded at } \mathrm{S} \text {. } \\
\text { Kensington in } \\
\text { gram calories } \\
\text { per sq. cm. of } \\
\text { horizontal sur- } \\
\text { face per day } \\
=\mathrm{R} .\end{array}$ & $\begin{array}{l}\text { Calculated mean } \\
\text { daily gain or } \\
\text { loss of heat per } \\
\text { sq. cm. due to } \\
\text { evaporation,ete. } \\
\text { (C- }-\mathrm{R} \text { ). } \\
=\mathrm{E} .\end{array}$ & $\begin{array}{l}\text { Mean aqueous } \\
\text { vapour pres- } \\
\text { sure of surface } \\
\text { water at E1 less } \\
\text { that of air at } \\
\text { Cattewater Air } \\
\text { Station. } \\
\text { Ps-Pa. }\end{array}$ \\
\hline & & & & cals. & cals. & cals. & \\
\hline Mar. & . & . & $-\cdot 3$ & -68 & 57 & -143 & $2 \cdot 1$ \\
\hline April & . & . & $+1 \cdot 0$ & +233 & 204 & +29 & \\
\hline May & . & . & $+1 \cdot 3$ & +293 & 332 & -39 & \\
\hline June & . & . & $+1 \cdot 4$ & +326 & 387 & -61 & \\
\hline July & . & . & +8 & +180 & 379 & -199 & \\
\hline Aug. & . & . & $+\cdot 25$ & +57 & 311 & -254 & \\
\hline
\end{tabular}

Several features are very noticeable. The water gained heat each year between dates very close to those of the spring and autumn equinox, except in 1921, when a big influx of warm Atlantic water occurring during the months of September, October and November, postponed the onset of loss of heat by nearly a month. This is clearly shown in Table I.

The gain is not equal to the subsequent fall during the winter months, and is not the same each year. The gain or loss of heat during the same month varies considerably from year to year, even in months when there is no evidence of decided water movement.

Although not relevant to the matter being dealt with, it is of interest to note that the curves drawn for the temperature changes of various layers of water at E1, from surface to bottom, and of surface water of the inshore stations between E1 and Plymouth all have the general form of those for the column of water shown in Fig. 1, and are very notably similar during the winter months. It is of interest also to note that the winter herring fishery (January) from this port resulted in very poor catches during the warm winter of 1921, in moderate catches in 1922, and in good catches during the cold winter of 1923 .

The main source of heat gain by the sea is that due to direct and diffuse solar radiation, which is absorbed by the surface layers. In experiments (5) made in the Nyhammer oyster basin the heat did not penetrate perceptibly below 5 metres. As the sea acts almost as a perfect radiator (4) or black body, practically all the solar radiation will be absorbed.

A main source of loss of heat by the sea appears to be evaporation, judging by the observations made in this area. Other sources are loss into space from radiation (5) and conduction to the atmosphere. 
In the area under consideration variations in the loss from radiation appears to be overshadowed by the loss from evaporation, on comparing the same month of different years.

Heat will also be lost by heating the atmosphere, but the amount is likely to be small since one gram calorie will heat a column of air 1 square centimetre in section and ca. 30 metres high through $1^{\circ} \mathrm{C}(5)$. The loss of 1 gram calorie, on the other hand, will be caused by the evaporation of one six-hundredth of a cubic centimetre of water at sea temperature.

The heat in calories required to raise $1 \mathrm{cc}$. of sea water through $1^{\circ} \mathrm{C}$. is taken as the round figure 1.0 in the calculations made in this paper.

It is noteworthy that in discussing cooling of the sea, Helland-Hansen makes no mention of the losses caused by evaporation.

\section{Summer Gain in Heat.}

Considering the rise in temperature during the summer months, early in May the upper layers show signs of being heated by solar radiation, provided that windy weather and consequent vertical mixing by wave motion does not hide this effect, as in May, 1923. This condition continues throughout the summer, until some time in September, unless vertical mixing occurs, as in July, 1922.

Once such a warm upper layer is well established, with its sharp line of discontinuity with the colder and denser water below, it is remarkably stable; several days of rough sea are necessary to alter it materially.

While the layer lasts, less saline shore water which has remained heaped up close to the land during the winter tends to run out, and to mix with this less dense upper layer (6). Rain falling on the sea will not penetrate below the layer of discontinuity. The fall of an inch of rain will have a marked effect on the salinity of the relatively shallow upper layer.

During September as the amount of solar radiation becomes Jess and the day shorter, while the heat loss by evaporation continues, the surface water cools sufficiently during the night to sink deeper, until this vertical movement combined with that of wave motion, finally breaks down the discontinuity layer.

Conditions which tend towards the formation and continuation of a warm upper layer are excess of solar radiation over heat loss by evaporation (i.e. warming of the surface), and lack of strong winds with their consequent vertical mixing by wave motion. These same conditions will allow, at times, considerable evaporation, owing to the upper inch or two of water becoming very hot.

The surface sample dipped up with a bucket represents the surface 
6 inches, more or less, and will be considerably cooler than the actual surface during a hot sunny day with little wind (8). Such a sample has been taken in August at E1 and registered over $19^{\circ} \mathrm{C}$.

The condition of the sea during the summer months leads to the seeming paradox that, during a summer month of light winds and high surface temperature, the heat gained by the sea may be less than during a summer month marked by less solar radiation and more wave motion.

Fig. 2 represents the vertical distribution of temperature in 1922 and

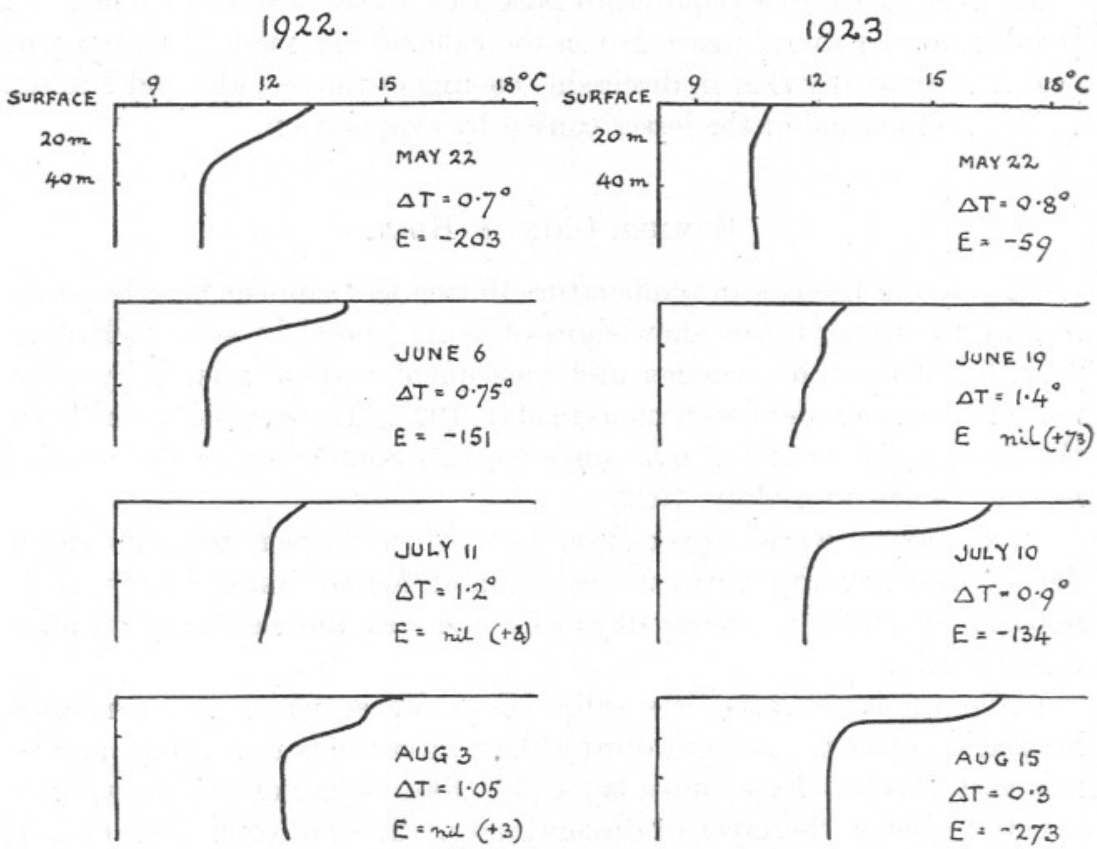

FIG. 2.-Black line shows the distribution of temperature with depth at Station E1 during the summers 1922, 1923. $\Delta \mathrm{T}$ shows the change in temperature of the whole column of water, as if mixed, during the calendar month.

$\mathrm{E}$ is the calculated mean daily loss in calories per sq. cm. due to evaporation, etc. (see p. 686.)

1923 ; a certain amount of water movement, as indicated by the changes in salinity, was undoubtedly taking place in 1922, but during these months of 1923 there is less evidence of any movement. It is very apparent that where a warm upper layer is present with consequent evaporation, the gain in heat $(\triangle \mathrm{T})$ by the water below is decreased.

Table IV and also the third column of Table II show the solar radiation recorded at South Kensington in gram calories falling on a horizontal square centimetre per day. The quantity will be greater at E1, owing to the clearer atmosphere for the most part and to the more southern latitude to a less extent. 


\section{TABLE IV.}

\begin{tabular}{|c|c|c|c|c|c|}
\hline & & 1921. & 1922. & 1923. & 1924. \\
\hline May & . & . $\quad 359$ & 361 & 239 & 332 \\
\hline June & - & . 411 & 326 & 254 & 387 \\
\hline July & - & . 394 & 267 & 337 & 379 \\
\hline August & . & . 284 & 244 & 341 & 311 \\
\hline
\end{tabular}

Solar radiation per horizontal square centimetre per day at South Kensington.

During the summers of 1922 and 1923, when solar radiation was high, wind conditions permitted a warm upper layer to be formed with sharp discontinuity with the water below; this allowed high-surface temperatures to be attained and the sea lost by evaporation a large proportion of its gross gain from solar radiation. Hence the net gain of heat by the sea was less than during the months when solar radiation was low. The following shows this :-



The fourth column in Table II shows the mean daily gain or loss of heat through one square centimetre of surface minus the solar radiation recorded at South Kensington.

Since the sea behaves practically as a full radiator (4), this difference represents heat lost by the sea due to evaporation, radiation and conduction, during those months when water from other areas had not moved into the E1 area.

During the summer months of 1922 and 1923, the monthly mean temperature of the air on Plymouth Hoe did not vary by more than about $1^{\circ} \mathrm{C}$. from the monthly mean temperature of the surface six inches of the sea. The sea temperature was obtained by drawing a fair curve through points showing the temperatures of the surface samples taken plotted 
against time. The temperature of the surface itself would be greater by day and rather less by night (diurnal variation).

This small difference in temperature would indicate that little heat is lost or gained in the twenty-four hours by conduction to and from the atmosphere during these months.

Hence the value, denoted by $\mathrm{E}$ in Fig. 2, being the difference between the mean daily gain in heat and the solar radiation, represents a loss which is due almost entirely to evaporation and radiation from the sea.

With regard to that moiety of the value of " $\mathrm{E}$," which is due to radiation outwards from the sea, the following considerations are of interest. The wave length (mean ca. $10 \mu$ ) is considerably longer than that of solar radiation (mean ca. $0 \cdot 1 \mu$ ). Hence it will be more readily absorbed by the moist atmosphere above the surface of the sea, which, forming a blanket, will retard radiation into space.

This value of $\mathrm{E}$, rough as it necessarily is, indicates even more plainly than the temperature change the effect of a surface layer of warm water.

These considerations indicate that the variations in heat gained by the sea between one summer and another are probably caused by increased evaporation during calm weather just as much as by movements of water from other areas. Variations in solar radiation from year to year play a part not so much by varying the quantities of heat absorbed by the sea, as by modifying the conditions which determine the loss by evaporation.

Comparing, month for month, the values of solar radiation shown in Table IV with the vertical distribution of temperature, as shown in Figs. 2 and 3 , it is at once apparent that the greater the solar radiation, the greater is the tendency towards a well-marked discontinuity layer which withstands the action of wave motion. Unfortunately there were no observations made in June, 1921 ; but, judging from the vertical distribution on July 2nd and the condition on May 26th, vertical mixing prevailed. During May and June the salinity was rising quickly; probably warmer water from the south was entering the area. During 1922 a warm upper layer was well formed in June, but broken up again by wave motion combined with reduced solar radiation in July. In 1923 the solar radiation was low until July, and did not overcome the vertical mixing by wave motion until that month, when increased radiation allowed the establishment of a warm layer.

It is contended that the general agreement between the condition of the upper layers and the value of $\mathrm{E}$ (Fig. 2) in itself indicates that the movements of the water mass were not very extensive. The calculated value $\mathrm{E}$ would be considerably affected by the inflow of warmer water 
from shallower inshore areas, or from the Atlantic, or of colder water from the Irish Channel.

Turning to a consideration of the conditions during the summers of 1921 and 1924, salinity changes indicate replacement of water at E1 by water from other areas. It is of interest to see whether, when the value of $\mathrm{E}$ appears high for the general conditions (July, 1921, Fig. 3), there is any evidence of eolder water entering the area.

"During 1921, in July, there was a marked check in the increase in

1921.

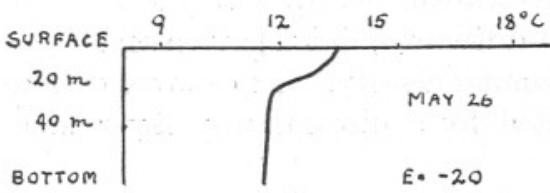

.

NO OBSERYATIONS JUNE

$$
E=-1001
$$
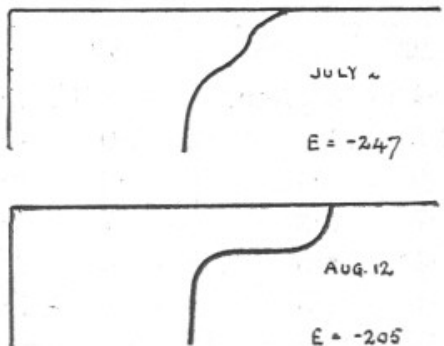

1924.


E. -199

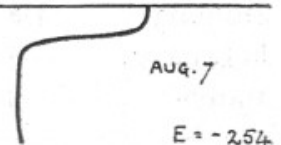

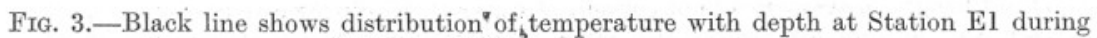
the summers of 1921 and 1924

$\mathrm{E}$ is the calculated "mean daily loss in calories per sq. cm. due to evaporation, etc.

temperature of the 'deep water' at E1, coincident with a fall in salinity . . . a tongue of less saline and colder water from the south of the Irish Channel had extended up the centre of the English Channel (2)." This was written before any detailed investigation on the effect of evaporation on the seasonal changes in temperature was undertaken.

The value of E for June, 1924 (Fig. 3), was low while layering was marked. This would suggest that warmer water entered the area during the month. Salinity data indicate that probably two movements took place between May 20th and June 17th. Less saline water moved out further seaward from the shallower inshore grounds. Water occupying 
the E2 area (centre of channel) on May 20th, when it was both warmer and less saline than the water at E1, moved northward into the E1 area by June 17th. From June 17th until July 10th there was probably little or no water movement at E1. The salinity data available afford no proof that warmer water moved into the El area during June, 1924, but the evidence they afford is certainly more in favour of such a movement than otherwise.

\section{Loss of Heat in Winter.}

By the end of September the temperature of the sea is very nearly the same from top to bottom. Layers of different salinity have been mixed so that the whole mass of water is of similar density. Hence water cooled at the surface will sink uninterrupted by a discontinuity layer with denser water below it.

The atmosphere cools more rapidly than the sea, the vapour pressure

TABLE III.

\begin{tabular}{|c|c|c|c|c|c|c|}
\hline \multirow[t]{2}{*}{$\begin{array}{l}\text { Calendar } \\
\text { month. }\end{array}$} & \multicolumn{2}{|c|}{$1921-22$} & \multicolumn{2}{|c|}{$1922-23}$. & \multicolumn{2}{|c|}{ 1923-24. } \\
\hline & $\Delta \mathrm{T}$ & $\mathrm{Ps}-\mathrm{Pa}$ & $\Delta \mathrm{T}$ & $\mathrm{Ps}-\mathrm{Pa}$ & $\Delta \mathrm{T}$ & $\mathrm{Ps}-\mathrm{Pa}$ \\
\hline October & $+\cdot 4^{\circ} \mathrm{C}$ & $2 \cdot 6 \mathrm{~mm}$ & $-1 \cdot 4^{\circ} \mathrm{C}$ & $4 \cdot 2 \mathrm{~mm}$. & $-\cdot 7^{\circ} \mathrm{C}$. & $2.8 \mathrm{~mm}$. \\
\hline November & $-1 \cdot 45$ & $4 \cdot 7$ & $-1 \cdot 5$ & $3 \cdot 1$ & $-2 \cdot 0$ & $4 \cdot 1$ \\
\hline December & $-1 \cdot 8$ & $3 \cdot 4$ & -.9 & $2 \cdot 4$ & $-1 \cdot 2$ & $2 \cdot 1$ \\
\hline January & $-1 \cdot 3$ & 2.5 & $-\cdot 7$ & $2 \cdot 2$ & $-\cdot 7$ & $1 \cdot 5$ \\
\hline February & $-\cdot 8$ & $2 \cdot 2$ & $-\cdot 4$ & $1 \cdot 5$ & $-\cdot 6$ & $1 \cdot 2$ \\
\hline March & $-\cdot 3$ & $2 \cdot 9$ & $+\cdot 1$ & 1.5 & $-\cdot 3$ & $2 \cdot 7$ \\
\hline
\end{tabular}

$\Delta T$.-Changes in temperature of column of water at El during calendar months when surface and bottom are nearly the same temperature. $\mathrm{Ps}-\mathrm{Pa}$-Difference between the aqueous vapour pressure of the surface water at El and the mean vapour pressure of the air at Cattewater Air Station for each month.

of its contained water vapour falling more rapidly than the vapour pressure of the surface water falls. From October to December the condition is likely to arise of a considerably greater aqueous vapour pressure of the surface water than in the air blowing over it. This will lead to increased evaporation. After December the air temperature tends to rise, while the sea surface temperature continues to fall, hence after December the difference in aqueous, vapour pressure between sea surface and air will tend to increase.

Reference to Table III and Table II shows that the major heat loss by the sea occurs before the end of December, except in 1921 when the 
influx of warm Atlantic water postponed the fall in temperature until November.

The mean observed aqueous vapour pressure of the air at Cattewater Air Station, Plymouth, as published every month by the Meteorological Office ( $\mathrm{Pa}$ in Tables II and III) was deducted from the calculated aqueous vapour pressure of the surface water at E1 (Ps). From this columns $\mathrm{Ps}-\mathrm{Pa}$ were constructed.

Values of Ps for the summer months were not calculated, because a single monthly observation of the surface six inches affords no indication of the mean value of the actual surface temperature for the month.

The values of $\mathrm{Ps}-\mathrm{Pa}$ during the winter half year should give a rough value of the difference in aqueous vapour pressure of the surface of the sea and of the air blowing over it, Cattewater Air Station being in a fairly exposed position.

Considering the rough nature of this value, $\mathrm{Ps}-\mathrm{Pa}$, there is good general agreement between it and the fall in temperature during the same month of the two years.

The values for mean daily loss of heat per day minus the solar radiation ("calculated loss in calories due to evaporation, radiation," etc.) show an extraordinarily close agreement with the difference in aqueous vapour pressure between sea and air. This is particularly noticeable during those months when the salinity changes are slight.

Fig. 4 (p. 690) shows this correlation very plainly.*

The magnitude of this loss of heat due to evaporation when Ps-Pa reaches a high figure is considerable. A period marked by dry cold atmospheric conditions will have as great an effect on the temperature of the sea as many considerable water movements.

With regard to other factors than $\mathrm{Ps}-\mathrm{Pa}$ which promote evaporation, " all observers agree that evaporation increases with wind velocity. . . . The wind usually has a variable vertical component, and, besides, is irregular in strength and direction. There is not, therefore, any constant relation of evaporation to the average horizontal component of wind velocity, the value usually measured"( $(\mathbf{y})$. I have been unable to find any correlation between the amount of wind during the month and either the fall in temperature or "loss of heat due to evaporation," etc. It appears that in the open sea the wind factor is overshadowed by that of difference of vapour pressure, on comparing sufficiently long periods of time.

It is of interest to compare the total evaporation and rainfall during the year. Assuming that the values given in column 4 of Table II are

* During January and February, 1924, there was a marked fall in salinity at El. On reference to Fig. 2, the loss of heat minus solar radiation appears somewhat greater than would be accounted for by evaporation, due to the difference in vapour pressure between the sea surface and the air. 

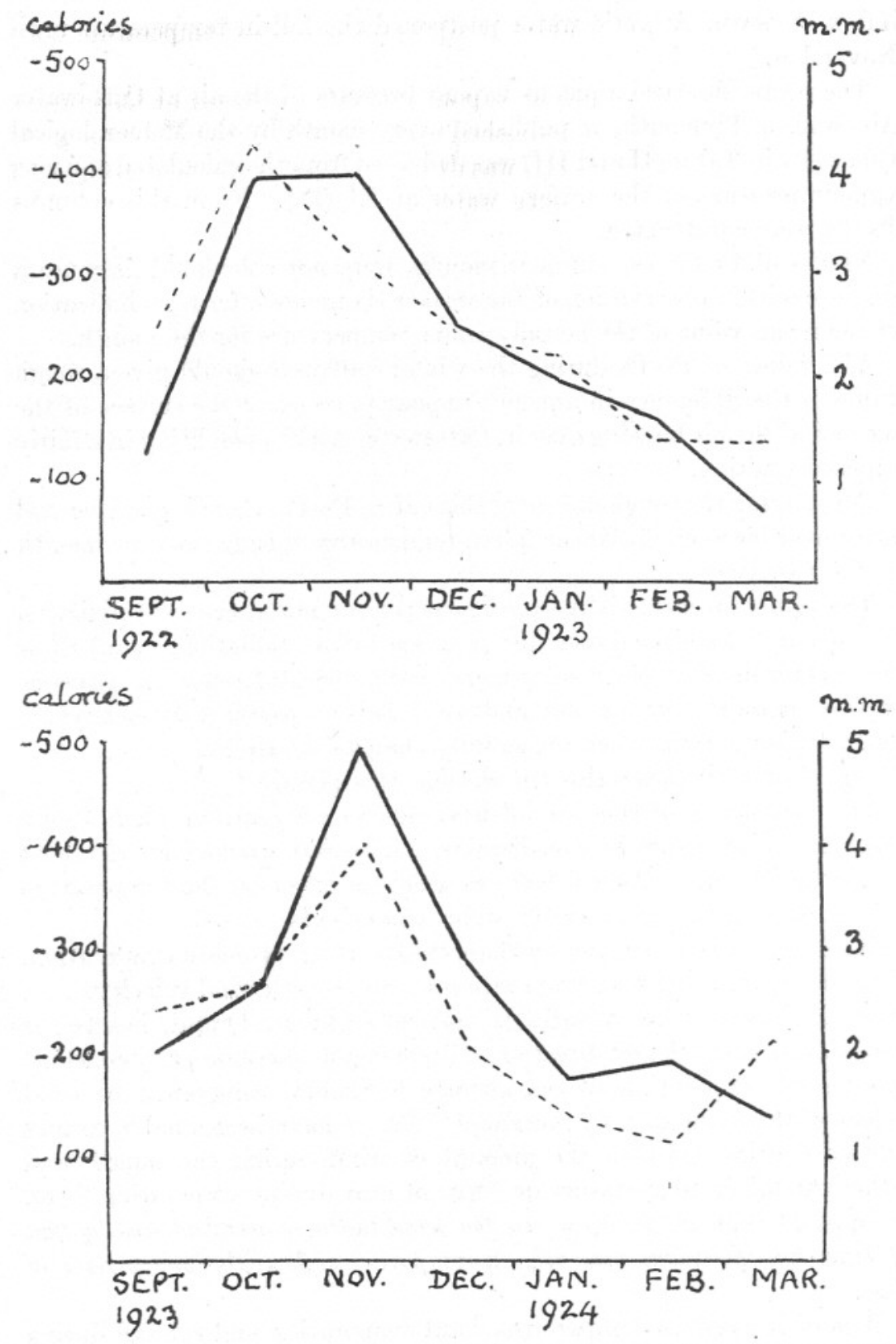

FIG. 4.-Thick line shows loss of heat per day by column 1 sq. cm. in section, from surface to bottom, at El, minus solar radiation per horizontal sq. cm., as recorded at South Kensington.

Dotted line shows difference in aqueous vapour pressure between surface water at El and the air at Cattewater Air Station Observatory. 
correct and* the loss of heat is due entirely to evaporation during the ten months of 1922 for which the value is recorded, an average of 173 calories per day is lost per square centimetre. This is roughly 63,000 calories, sufficient to account for the evaporation of a depth of 100 centimetres of water during the year. This is approximately equal to the year's rainfall (Plymouth, $93 \mathrm{~cm}$. and Falmouth, $116 \mathrm{~cm}$.). During 1923 evaporation was 110 cubic centimetres, and rainfall at Plymouth 86 cubic centimetres, and at Falmouth 115 cubic centimetres per square centimetre.

The area under consideration will also receive some of the rainfall over neighbouring land, particularly in the summer, when it tends to run out as a surface layer. This leads to the conclusion that if no water movement was taking place dilution by rainfall and coast water would probably be almost balanced by evaporation from the sea in this particular area.

\section{Conclusions.}

Evaporation from the sea surface plays an important part in modifying the annual rise and fall in temperature of the sea.

A hot summer with light winds gives rise to high surface temperatures and considerable loss of heat by evaporation.

During the winter half year the total loss of heat by the sea, allowing for the heat gained by solar radiation, shows a remarkable proportionality to the difference in aqueous vapour pressure between surface water and the air.

The change of temperature of the sea, during the period considered, was controlled to a marked extent by evaporation from the surface, except during the very considerable inflow of Atlantic water in September and November, 1921.

In the open sea difference in aqueous vapour pressure between surface water and air is the major factor controlling evaporation, overshadowing the effect of wind, when sufficiently long periods are compared.

I am indebted to my colleagues, and in particular to Dr. W. R. G. Atkins, for many valuable suggestions during the course of this investigation. Dr. H. Stanley Allen, who read the draft of this paper, has suggested that it may be possible to calculate the moiety of the value of " $\mathrm{E}$ " which is due to radiation outwards.

* The mean daily solar radiation is that recorded at South Kensington, and the mean daily loss or gain of heat by the sea at El is taken from a "fair " curve drawn through points roughly one month distant, hence the values shown can only be roughly representative. That moiety of the value of $\mathrm{E}$, which is due to radiation outwards, may, during some months, be considerable. 


\section{LIST OF LITERATURE.}

1. Orton, J. H. Journ. Mar. Biol. Assoc,, Vol. XII, No. 2, p. 339, July, 1920.

2. Harvey, H. W. Journ. Mar. Biol. Assoc., Vol. XIII, No. 1, pp. 230, 231, Dec., 1923.

3. Le Danors. Rapports Atlantique, 1921, 1922 and 1923. Cons. Perm. pour l'exp. de la Mer. Copenhagen. Off. Sci. et Tech. des Peches maritimes Notes et Memoires, No. 36. Paris, 1924. Annales de l'Institute Oceanographique, Nouvelle Serie, Tome I, Fasc. I. Paris, 1924.

4. Boys, C. V. Dict. Applied Physics, Vol. III, p. 713. London, 1923.

5. Helland Hensen. The Ocean Waters. Internat. Review Hydrobiol. Hydrog. Suppl., Series I, p. 64 et seq. Leipzig, 1911.

6. Sandstrom, J. Hydrodynamies of Canadian Atlantic Waters. Canadian Fish Expdn., 1914-15. Ottawa, 1918.

7. Humphreys. Physics of the Air, p. 249. Philadelphia, 1920.

8. Aтkins, W. R. G. Journ. Mar. Biol. Assoc., Vol. XIII, No. 2, p. 319 , Nov., 1924. 